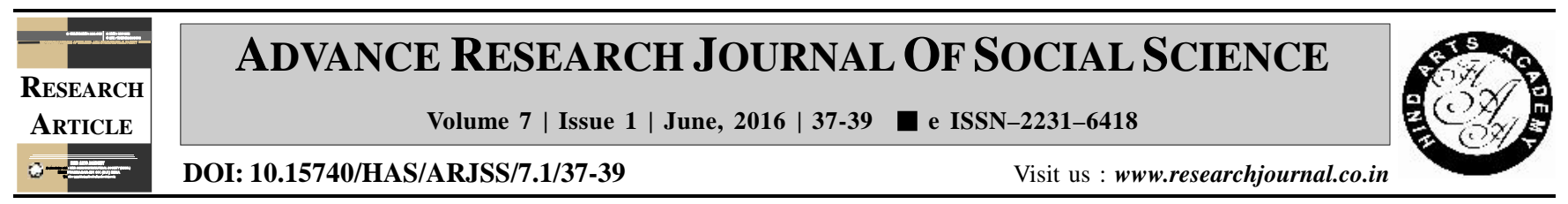

\title{
Home environment of late adolescent boys and girls belonging to nuclear family
}

\section{Sati* and S. Gir}

Department of Human Development and Family Studies, College of Home Science, Maharana Pratap University of Agriculture and Technology, UDAIPUR (RAJASTHAN) INDIA

(Email: latasati90@gmail.com)

\section{ARTICLE INFO :}

$\begin{array}{lll}\text { Received } & : & 21.12 .2015 \\ \text { Revised } & : & 28.03 .2016 \\ \text { Accepted } & : & 07.05 .2016\end{array}$

KEY WORDS :

Home environment, Nuclear family, Adolescents

HOW TO CITE THIS ARTICLE :

Sati, L. and Gir, S. (2016). Home environment of late adolescent boys and girls belonging to nuclear family. Adv. Res. J. Soc. Sci., 7 (1) : 37-39, DOI: 10.15740/ HAS/ARJSS/7.1/37-39.

*Author for correspondence

\begin{abstract}
The present study was an attempt to assess and compare the home environment of late adolescent boys and girls residing in nuclear family. The total sample for the present study consisted of 120 late adolescent boys and girls. The sample was selected from 6 non-coeducational government schools of Udaipur city. A preliminary survey was conducted among $11^{\text {th }}$ and $12^{\text {th }}$ class students to select the sample as per the delimitation of the study. To assess home environment, inventory developed by Mishra (1989) was administered. The data was collected, coded and analyzed. Frequency and percentage was computed for each category.
\end{abstract}

